\title{
Involvement of hydrogen-vacancy complexes in the baking effect of niobium cavities
}

\author{
B. Visentin, ${ }^{1, *}$ M. F. Barthe, ${ }^{2,3}$ V. Moineau, ${ }^{2,3}$ and P. Desgardin ${ }^{2,3}$ \\ ${ }^{1}$ CEA-Saclay, DSM/IRFU/SACM, 91191 Gif/Yvette Cedex, France \\ ${ }^{2}$ CNRS, UPR 3079 CEMHTI, ID Avenue de la Recherche Scientifique, 45071 Orléans Cedex 2, France \\ ${ }^{3}$ Université d'Orléans, Avenue du Parc Floral BP 6749, 45067 Orléans Cedex 2, France
}

(Received 30 November 2009; published 26 May 2010)

\begin{abstract}
Baking is necessary to improve high accelerating gradient performances of superconducting niobium cavities. Ten years after this discovery in 1998, the understanding of this effect still resists a lot of theoretical explanations. For the first time, positron annihilation spectroscopy performed on niobium samples reveals the increase after baking of positrons trapped under the $\mathrm{Nb}$ surface. Presence of hydrogenvacancy complexes and their dissociation by baking could both explain rf losses observed at high fields (Q drop) and its cure (baking effect).
\end{abstract}

DOI: 10.1103/PhysRevSTAB.13.052002

PACS numbers: 74.62.Dh, 78.70.Bj, 74.70.Ad, 84.40. $-\mathrm{x}$

\section{INTRODUCTION}

The "baking effect" refers to the improvement of performances of $\mathrm{Nb}$ superconducting radio frequency (SRF) cavities once they have been baked in a narrow range of temperature during a limited time. Baking is a necessary final stage in cavity preparation to reach high gradients. For the standard process [1], named "in situ UHV baking," the cavity is baked at $110-120^{\circ} \mathrm{C}$ for $48-60$ hours while its inner part is under ultrahigh vacuum. An alternative less time consuming process, called "fast argon baking" has also been proposed [2,3] and was successfully demonstrated on electropolished single cell cavities [4]. In that case, thermal treatment is made at higher temperature $\left(145^{\circ} \mathrm{C}\right)$ in oxygen-free atmosphere during 3 or even 2 hours as shown in Fig. 1.

Since the beginning, due to the presence of interstitial oxygen at the $\mathrm{Nb}_{2} \mathrm{O}_{5}-\mathrm{Nb}$ interface, oxygen diffusion has been suspected to play a role in the baking effect. Nevertheless, surface analyses by secondary ion mass spectroscopy (SIMS) [3] and by diffuse x-ray scattering [5] achieved on $\mathrm{Nb}$ samples have not shown significant diffusion of interstitial oxygen after baking, as illustrated in Fig. 2 taken from Ref. [3]. Moreover, cavity rf performances are much deteriorated when the diffusion of interstitial oxygen is noticed.

Even if interstitial oxygen diffusion cannot be involved, other species including hydrogen atoms and vacancies can diffuse at baking process temperatures. Presently, diffusion process is not the only mechanism put forward to explain Q drop and baking effect; other mechanisms based on hot spots [6], dislocations [7], interface tunnel exchange [8], and magnetic impurities in the oxide [9] are also investigated.

Concerning vacancies, several papers [10-13], related to body-centered cubic transition metals, mentioned possibil-

\footnotetext{
*bernard.visentin@cea.fr
}

ities of impurity-vacancy dissociation and vacancy migration occurring at such temperatures (from 230 to $420 \mathrm{~K}$ ). In these experiments, we point out that vacancies were artificially induced by electron or neutron irradiations. Nevertheless, these possible events involving vacancies and occurring at the baking effect temperature range are of paramount interest. In that context, we have decided to verify on $\mathrm{Nb}$ samples if baking could induce some modifications in the vacancy concentration profile [14].

\section{POSITRON ANNIHILATION SPECTROSCOPY}

As positrons can easily get trapped in metal vacancy defects, positron annihilation spectroscopy (PAS) is known to be very sensitive to detect open defects in solids and an excellent method to analyze their population.

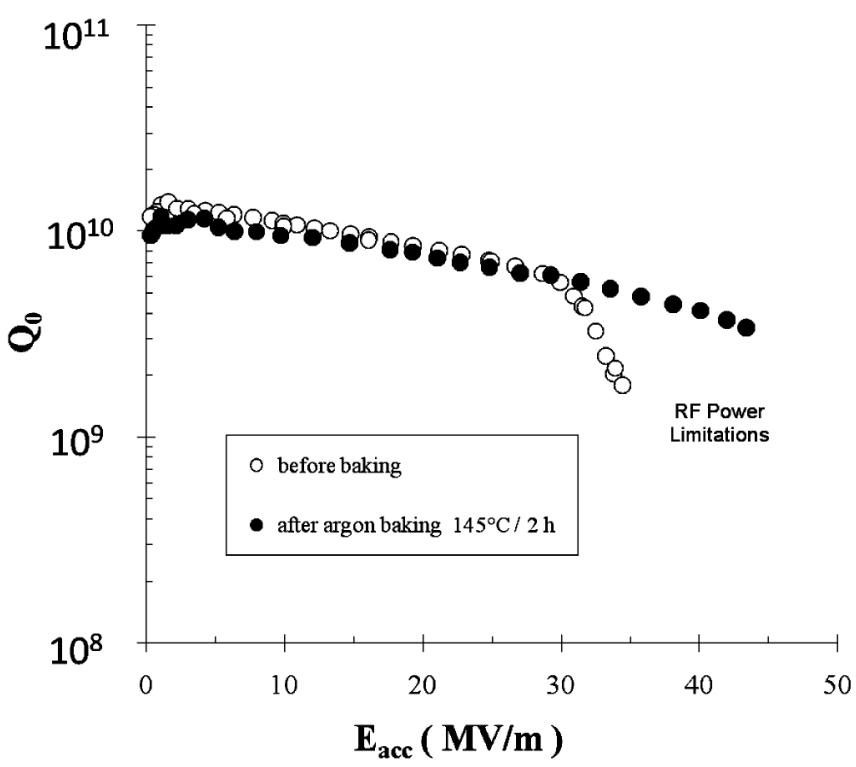

FIG. 1. "Fast baking" $\left(145^{\circ} \mathrm{C} / 2\right.$ hours) of single cell cavity in oxygen-free atmosphere (the cavity is filled with 1 atm of argon [14]). 


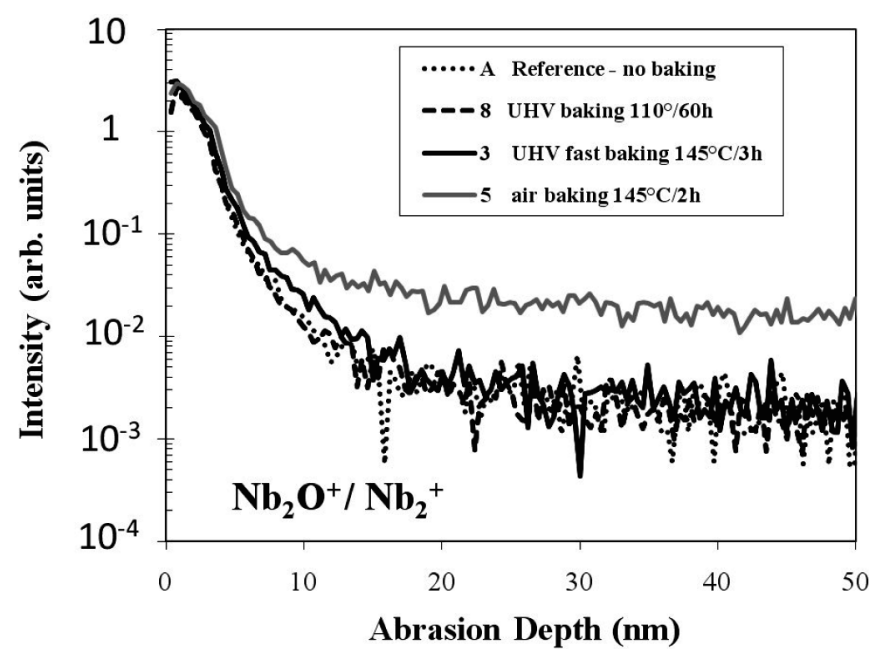

FIG. 2. Interstitial oxygen profiles in $\mathrm{Nb}$ samples by SIMS analyses. No difference before (sample A) and after baking in oxygen-free atmosphere (samples 8 and 3 ).

\section{A. Description}

When energetic positrons are implanted into a material, they are thermalized in a few picoseconds through inelastic collisions. Then, positrons diffuse in material and annihilate with electrons producing two $\gamma$ rays at $511 \mathrm{keV}$ in opposite directions. Before annihilation with electrons, positrons can be trapped in open-volume defects (dislocations lines, voids, vacancies, vacancy clusters ...) due to the repulsion by lattice ions. Positron annihilation spectroscopy [15] is based on the detection of the positron annihilation radiation. Among the three most important PAS techniques (positron lifetime detection, angular correlation, and $\gamma$-ray Doppler broadening), we will use the last one. In that technique the measured Doppler-shift of gamma rays is due to the center of mass motion of the annihilating positron-electron system. Positrons being thermalized, this broadening is only due to the electron momentum in the propagation direction. Two parameters $S=A_{S} / A_{0}$ (sharpness) and $W=A_{W} / A_{0}$ (wing) usually characterize the annihilation line shape. $A_{S}, A_{W}$, and $A_{0}$ are, respectively, the central, the lateral, and the total area of the annihilation line as mentioned in Fig. 3. In the case where positrons are trapped in vacancies, their lifetime is increased and the annihilation is preferentially done with valence electrons (small momentum), due to a lack of core electrons (high momentum), giving a smaller Doppler shift and a narrow line (Fig. 3). Although annihilation line is the superposition result of free and trapped positrons, the $S(W)$ plot gives specific information on a defect-rich sample $(S \uparrow, W \downarrow)$.

\section{B. Positron beam facility}

The positron beam facility in Orléans [16] provides monoenergetic positrons with variable energy up to

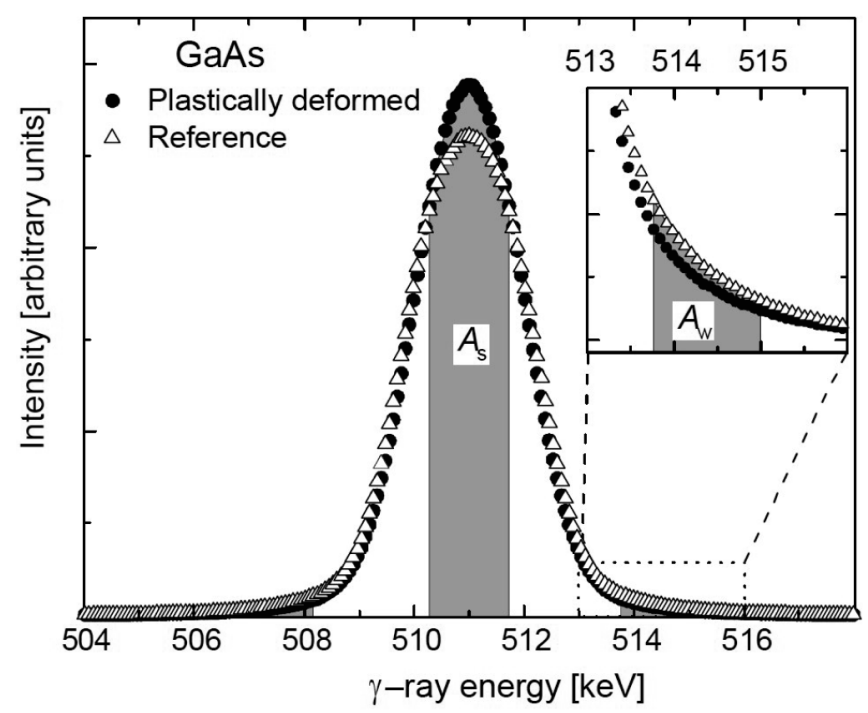

FIG. 3. Doppler broadening example of a positron annihilation radiation line. Dark dots correspond to a GaAs defect-rich sample and show a narrow line [23].

$25 \mathrm{keV}$; the setup is shown in Fig. 4. To obtain a monoenergetic beam, positrons emitted by a ${ }^{22} \mathrm{Na}$ radioactive source have to go through a $4 \mu \mathrm{m}$ polycrystalline $W$ foil: the moderator. Meanwhile most of the positrons leave the moderator with a high residual energy or stop in the foil before annihilation; a very small fraction of them $(0.05 \%)$ thermalizes, diffuses, and is spontaneously emitted by the moderator surface at a very low energy $(3 \mathrm{eV})$, due to the negative work function of tungsten. These monoenergetic slow positrons are then extracted, accelerated, and magnetically guided towards the sample-holder target; at this point the flux and the diameter of the positron beam are $2 \times 10^{5} \mathrm{e}^{+} \mathrm{s}^{-1}$ and $2 \mathrm{~mm}$. To detect the $\gamma$-ray Doppler broadening at $511 \mathrm{keV}$, the experimental chamber is equipped with a high purity germanium detector.

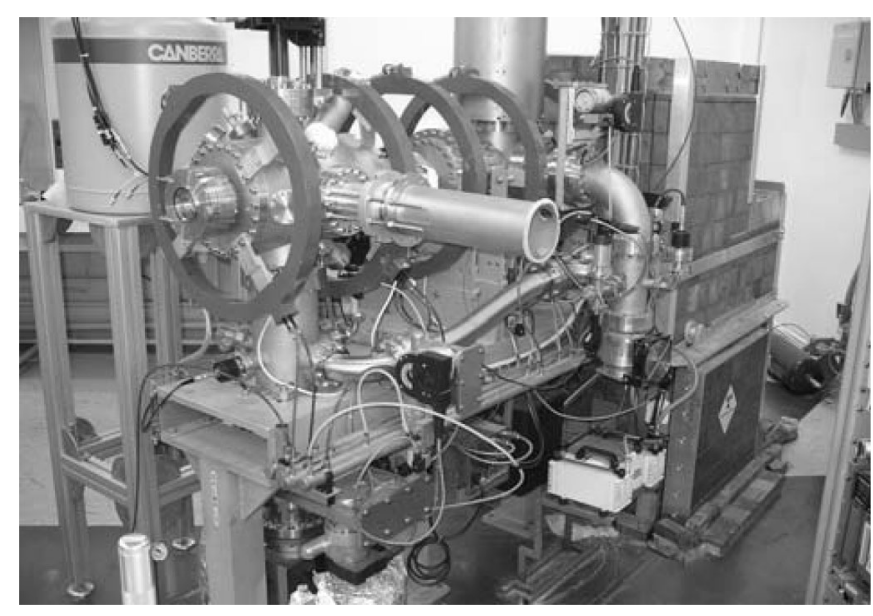

FIG. 4. Picture of the slow positron beam facility in Orléans. 
The Makhov formula (1) below allows calculating the positron implantation profile after thermalization and before particle diffusion in material:

$$
P(z, E)=\frac{2 z}{z_{0}} e^{-\left(Z / Z_{0}\right)^{2}}
$$

where

$$
z_{0}=\frac{A E^{\alpha}}{\rho \Gamma(3 / 2)} \equiv \frac{z_{m}}{\Gamma(3 / 2)} .
$$

Parameters $A$ and $\alpha$ are material dependent; $\rho$ is the mass density and $\Gamma$ the gamma function. The mean implantation depth $z_{m}$ and Makhov profiles are plotted in Figs. 5 and 6 with these parameters for niobium: $A=$ $2.95 \mu \mathrm{g} \mathrm{cm}^{-2} \mathrm{keV}^{-\alpha}, \alpha=1.7$, and $\rho=8.57 \mathrm{~g} \mathrm{~cm}^{-3}$.

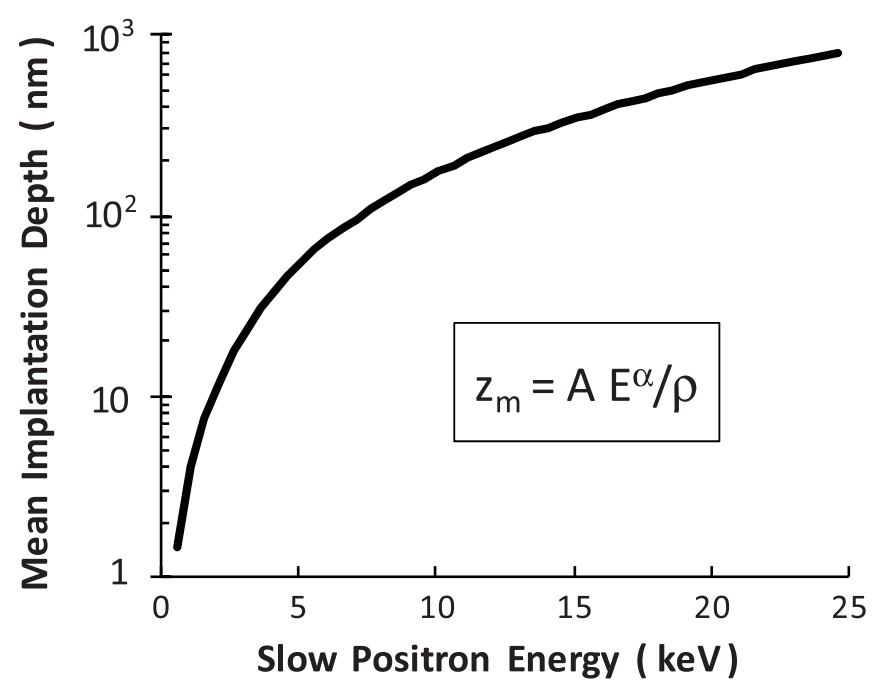

FIG. 5. Mean implantation depth in niobium versus positron beam energy.

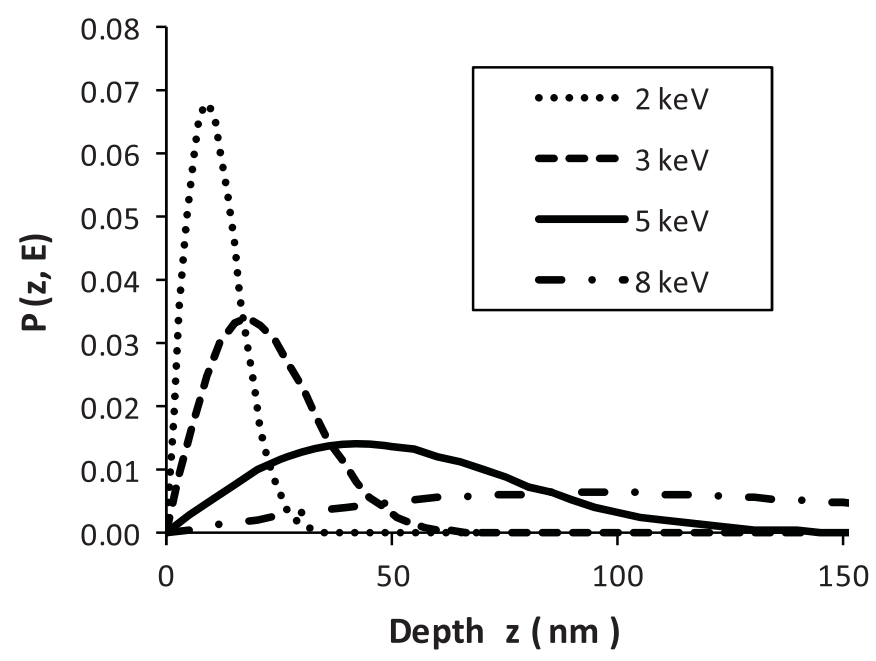

FIG. 6. Makhov profiles of positron penetration in niobium for different beam energies.

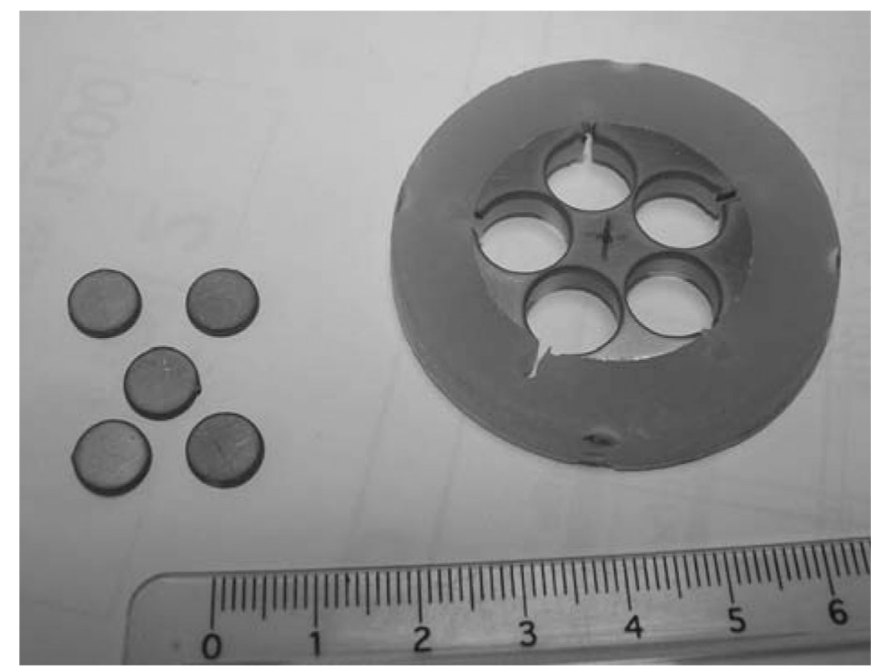

FIG. 7. Image of the five $S C$ samples (diameter $8 \mathrm{~mm}$ ) cut by water-jet from $\mathrm{Nb}$ sheet (diameter $30 \mathrm{~mm}$ ).

\section{NIOBIUM SAMPLES}

Niobium samples ( $8 \mathrm{~mm}$ diameter, $1 \mathrm{~mm}$ thickness) are cut out to the right diameter using a water-jet technique with abrasive garnet sand (Fig. 7). Two types of niobium samples are tested in this experiment: (i) Samples 1, 2, 3, and 4 are made from a single crystal $(S C)$ provided by Xenia Singer from DESY. It is more precisely the "beamaperture offcut" of a large grain $\mathrm{Nb}$ sheet (Heraeus-RRR 500). (ii) Samples $B, G$, and $H$ are made from a fine grain $(F G)$ niobium piece (Tokyo Denkai-RRR 200). Different treatments were applied to these samples and they are summed up in Table I below.

$S C$ samples are treated like SRF cavities by annealing under vacuum $\left(800^{\circ} \mathrm{C}-1 \times 10^{-7} \mathrm{mbar}\right)$ during 4 hours to remove hydrogen, then by buffered chemical polishing (BCP) to remove $100 \mu \mathrm{m}$ from the niobium surface.

$F G$ samples have undergone similar treatments; but to ensure a small surface roughness, BCP has been replaced by electropolishing (EP). Because of the sample dimensions, EP treatment took place before water-jet cutting. $F G$ samples were annealed during only 2.5 hours, compared to $S C$ ones, to prevent any grain growth at the surface. Nevertheless, hydrofluoric acid (HF) treatments have been applied on $F G$ samples before and after annealing to suppress any surface contamination.

At last, all samples underwent high pressure rinse with ultrapure water and air drying in clean room class 100. Moreover, some of them were baked at $145^{\circ} \mathrm{C}$ for 2 or 3 hours according to the "fast baking" process in $1 \mathrm{~atm}$ of argon (samples 3, 4, and $\mathrm{G}$ ) or air (sample $\mathrm{H}$ ).

\section{EXPERIMENTAL RESULTS}

The maximum positron beam energy ( $25 \mathrm{keV})$ corresponds to a mean implantation depth $\left(z_{m}\right)$ around $820 \mathrm{~nm}$ 
TABLE I. Characteristics and treatments of niobium samples.

\begin{tabular}{lcccccc}
\hline \hline $\begin{array}{l}\text { No. of } \\
\text { sample }\end{array}$ & $\begin{array}{c}\text { Niobium } \\
\text { structure }\end{array}$ & $\begin{array}{c}\text { EP chemistry } \\
(\mu \mathrm{m})\end{array}$ & $\begin{array}{c}\text { Water-jet } \\
\text { cutting }\end{array}$ & $\begin{array}{c}800^{\circ} \mathrm{C} \text { annealing } \\
\text { (hour) }\end{array}$ & $\begin{array}{c}\text { BCP chemistry } \\
(\mu \mathrm{m})\end{array}$ & $\begin{array}{c}145^{\circ} \mathrm{C} \text { baking } \\
\text { (hour) }\end{array}$ \\
\hline 1 and 2 & Single crystal & $\ldots$ & $X$ & 4.0 & 100 & $\ldots$ \\
3 and 4 & Single crystal & $\ldots$ & $X$ & 4.0 & 100 & 2 (argon) \\
$B$ & Fine grain & 500 & $X$ & 2.5 & $\ldots$ & $\ldots$ \\
$B^{*}$ & Fine grain & 500 & $X$ & 2.5 & 150 & $\ldots$ \\
$G^{*}$ & Fine grain & 500 & $X$ & 2.5 & 150 & 3 (argon) \\
$H^{*}$ & Fine grain & 500 & $X$ & 2.5 & 150 & 3 (air) \\
\hline \hline
\end{tabular}

(Fig. 5), deep enough to explore the superconducting rf layer of niobium $(\sim 50 \mathrm{~nm})$.

\section{A. Single crystal samples}

Low and high momentum annihilation fractions, $S$ and $W$ respectively, are recorded versus the incident positron energy as shown in Figs. 8 and 9. These tendency curves

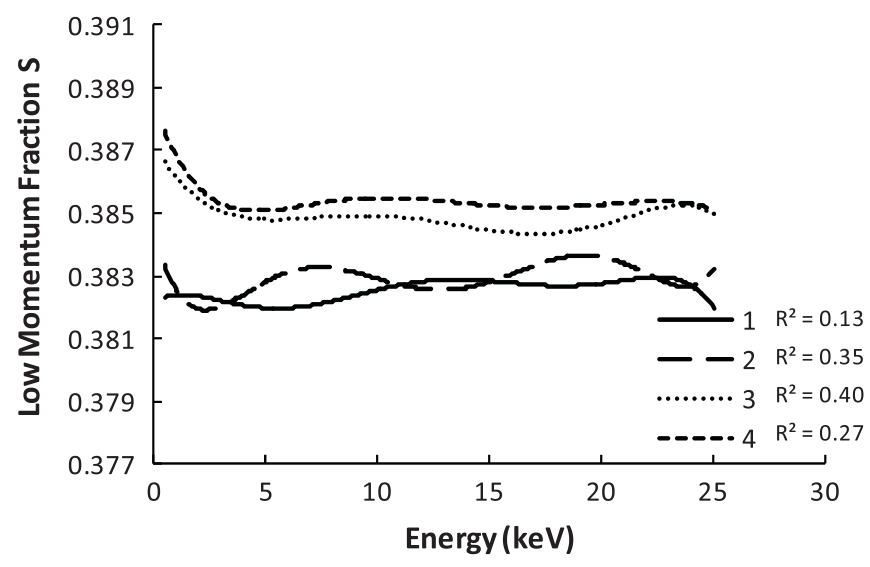

FIG. 8. Low momentum annihilation fraction $S$ vs positron energy for unbaked $(\# 1, \# 2)$ and baked $(\# 3, \# 4)$ single crystal $\mathrm{Nb}$ samples.

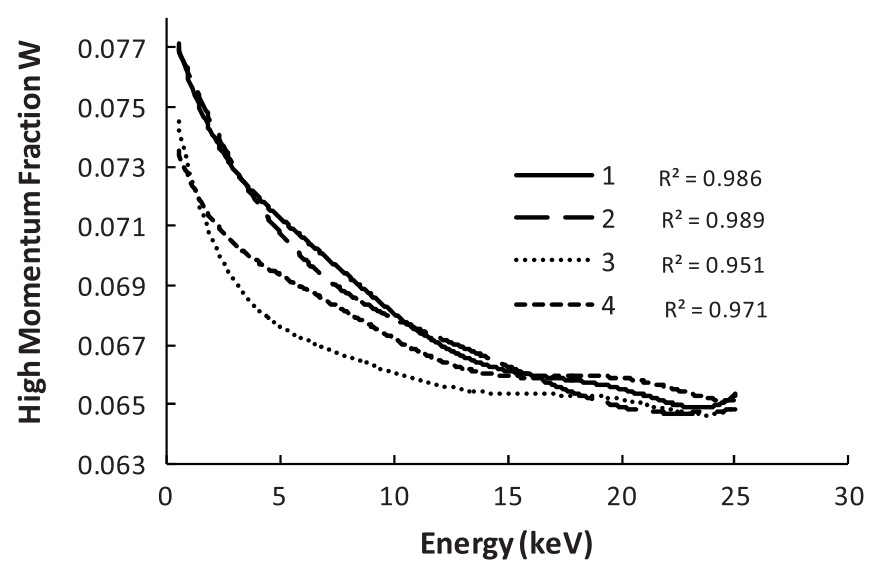

FIG. 9. High momentum annihilation fraction $W$ vs positron energy for unbaked (\#1, \#2) and baked (\#3, \#4) single crystal $\mathrm{Nb}$ samples. represent a polynomial fit of the raw data. It is important to note the reproducibility of these measurements between unbaked (\#1 and \#2) and baked samples (\#3 and \#4), because samples \#1 and \#4 are tested prior to \#2 and \#3 in different experimental runs far-off from two months. Moreover, we can clearly observe that baked $S C$ samples have higher $S$ and lower $W$ parameters than unbaked ones. In other words, the increase of vacancy sites is observed after baking and this consequence on positron trapping is mainly visible up to $8 \mathrm{keV}$, i.e., $120 \mathrm{~nm}$ of mean positron penetration depth. Variation between bulk and surface is more important for $W$ compared to $S$; this is probably due to the most important $W$ sensitivity to chemical surrounding of the annihilation sites.

\section{B. Fine grain samples}

Preliminary results reported in [14] and performed on electropolished $F G$ samples $B$ and $G$ were discordant compared to $S C$ ones, as shown in Fig. 10 (triangular data); surface contamination due to the preparation process has been suspected then. So these samples were treated by an additional $\mathrm{BCP}$ chemistry to remove additional thickness of $150 \mu \mathrm{m}$. To avoid any confusion with previous results of Ref. [14], these retreated samples are identified with an asterisk as described in Table I. This surface

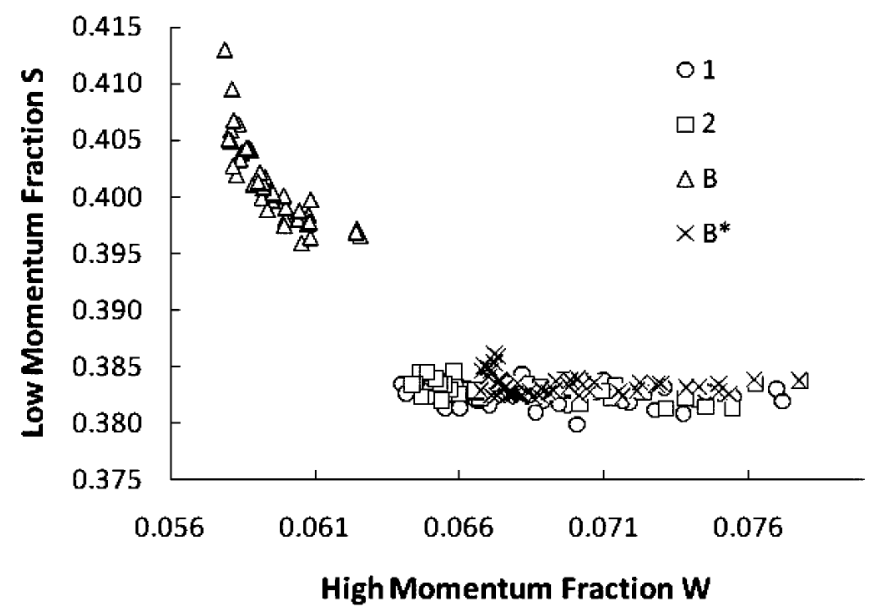

FIG. 10. $S$ versus $W$ plot for unbaked $S C$ and $F G$ samples (raw data). 


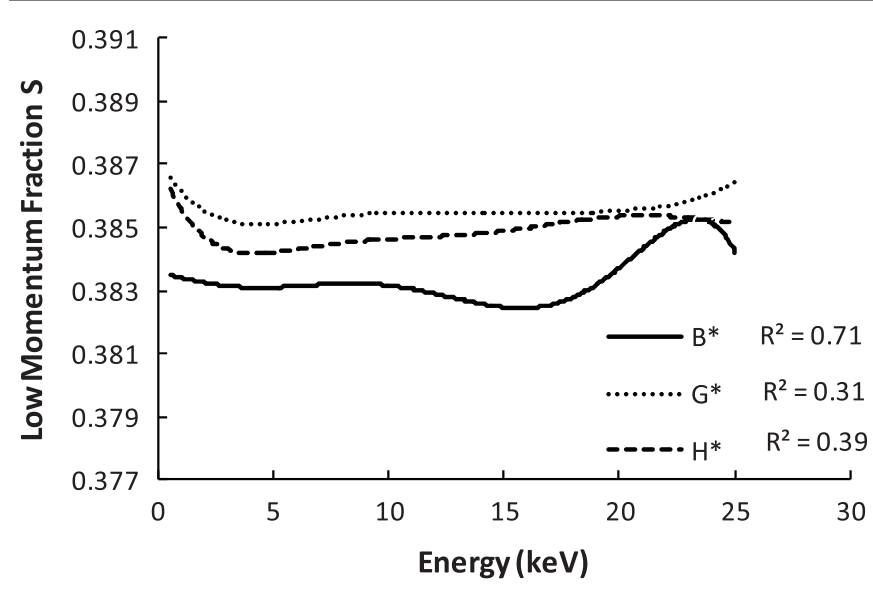

FIG. 11. Low momentum annihilation fraction $S$ vs positron energy for unbaked $\left(B^{*}\right)$ and baked $\left(G^{*}, H^{*}\right) F G$ samples.

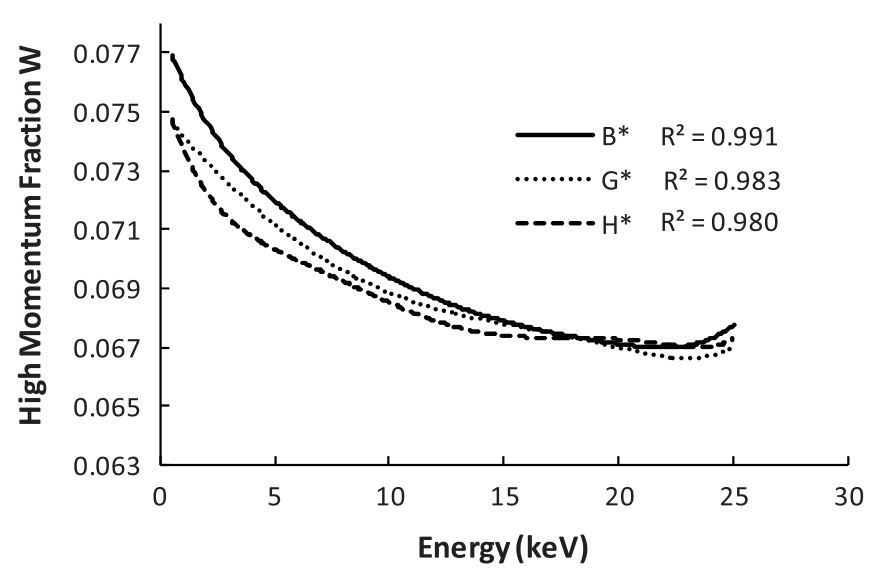

FIG. 12. High momentum annihilation fraction $W$ vs positron energy for unbaked $\left(B^{*}\right)$ and baked $\left(G^{*}, H^{*}\right) F G$ samples.

renewal provides more coherent results for the unbaked $B^{*}$ sample (cross data in Fig. 10).

Results of $F G$ sample analyses by positron annihilation are shown in Figs. 11 and 12; even if the effect is more pronounced for $S C$ samples, we have also noted an increase of vacancy sites after baking. No significant difference is observed between $G^{*}$ (argon baking) and sample $H^{*}$ (air baking); in consequence, the penetration of interstitial oxygen atoms, observed by SIMS analyses (sample 5 in Fig. 2), does not seem to be followed by the complexes' formation with $\mathrm{Nb}$ vacancies.

\section{COMMENTS}

In this experiment any vacancy migration and any vacancy decreasing are detected after baking on single crystal or fine grain $\mathrm{Nb}$ samples. On the contrary, the increase of vacancy sites is clearly observed. These results are in contradiction to those of Romanenko [7], where dislocation density (open defect) is found decreasing after baking and vacancy mobility is put forward to explain this observation.
Nevertheless, the vacancy increase after baking, observed in our experiments, is not so surprising if we consider the presence, argued below, of hydrogen-vacancy complexes $\left[\mathrm{H}-\mathrm{V}_{\mathrm{Nb}}\right]$ at the $\mathrm{Nb}$ surface. During baking, complexes are dissociated and hydrogen diffuses, avoiding any complexes rebuilding in the rf layer. More vacancy sites are then released for positron trapping in baked samples compared to unbaked ones.

Each part of this scenario is supported by following arguments: (i) The particular niobium affinity for hydrogen is not to be demonstrated any more. Besides, niobium annealing is recommended in cavity preparation to avoid hydride formation at low temperature and prevent rf losses so-called "Q disease" [17]. (ii) Even after this prior thermal treatment of $\mathrm{Nb}$ at $800^{\circ} \mathrm{C}$, new surface contamination by hydrogen is possible during each chemical treatment (BCP or EP). Hydrogen atoms coming from aqueous species are absorbed by the $\mathrm{Nb}$ surface. (iii) High hydrogen concentration near the niobium surface has already been measured by elastic recoil detection analysis $[18,19]$. (iv) $\mathrm{Nb}$ vacancies represent a potential well for hydrogen [20] and trapping of hydrogen is possible; position of hydrogen trapped around niobium vacancy has been calculated and schematically shown in Fig. 13. (v) Dissociation of impurity-vacancy complexes, including $\left[\mathrm{H}-\mathrm{V}_{\mathrm{Nb}}\right]$, is suggested to explain migrations of $\mathrm{Nb}$ vacancy observed between 230 and $400 \mathrm{~K}$ [10-13]. (vi) With a diffusion coefficient around $2 \times 10^{-5} \mathrm{~cm}^{2} \mathrm{~s}^{-1}$ at $400 \mathrm{~K}$ [21], the hydrogen atom can easily move after complex dissociation far from the surface.

Moreover, the involvement of hydrogen-vacancy complexes explains the observed fact [22] that baked cavities keep their improved performance during several years as long as they are not retreated by additional chemistry, i.e., the niobium surface is not exposed to hydrogen contamination. Taking all these remarks into account, we conclude that the scenario based on the presence of hydrogenvacancy complexes is consistent with our experimental findings.

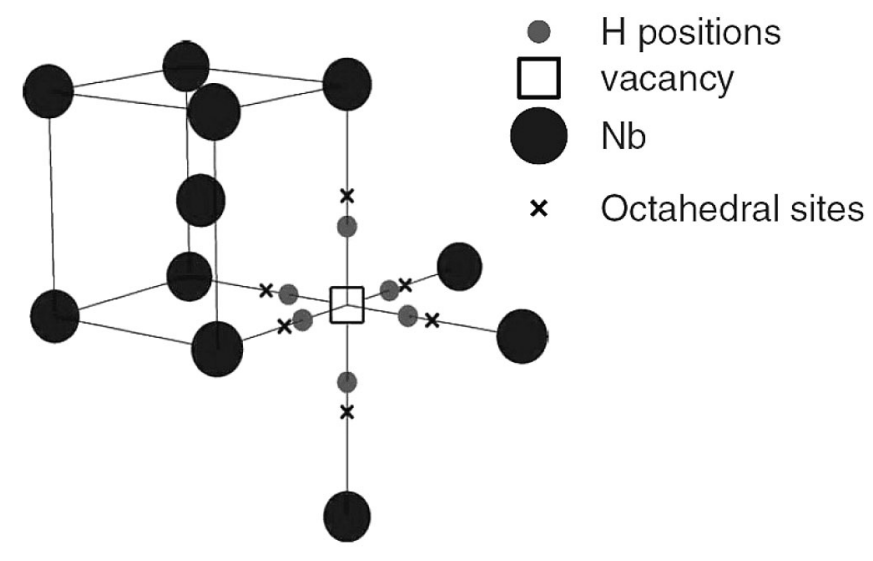

FIG. 13. Six possible lowest-energy sites for a single $H$ atom trapped in $\mathrm{Nb}$ vacancy [20]. 
Nevertheless it is necessary to rule out the $\mathrm{Nb}$ surface recontamination by hydrogen after hydrofluoric acid rinse, air exposure, and high pressure rinse. Even if previous experiments on Q disease [18] have not detected any contamination by hydrogen after cavity surface exposure to acid bath ( $\mathrm{HCl}$ for 24 hours, $\mathrm{HF}$ for $15 \mathrm{mn}$ ) and followed by high pressure rinse, it is necessary to confirm validity of these observations in our context. With this purpose in mind, experiments will be carried out with the elastic recoil detection analysis (ERDA) method applied to our samples.

\section{CONCLUSION}

These experiments on positron annihilation have been performed on $\mathrm{Nb}$ samples to define a possible involvement of vacancies in the baking effect. Single crystal and fine grain samples, treated by chemical etching, have been analyzed by positron annihilation spectroscopy through the radiation Doppler broadening method. For the first time, an increase of vacancy sites is clearly observed. The depth concerned by the vacancy increase is a wide overlap of the superconducting rf layer. To explain these results, we suggest the presence of hydrogen-vacancy complexes, dissociated by baking and followed by hydrogen diffusion. Thus hydrogen, already responsible of $\mathrm{Q}$ disease through niobium hydrides, could be also responsible for the nonquadratic losses at high fields (Q slope) through hydrogen-vacancy complexes.

As PAS is a nondestructive technique, we plan to determine hydrogen profiles by ERDA analyses on the same samples and by the way to link hydrogen and vacancy location before and after baking. In addition to that, we plan to modify the process of sample electropolishing, avoiding surface contamination. Then positron annihilation spectroscopy could be undertaken on electropolished $F G$ samples to understand why this chemical treatment is more efficient on SRF cavities.

\section{ACKNOWLEDGMENTS}

We express our gratitude to Xenia Singer from DESY for providing us with $\mathrm{Nb}$ single crystal, as well as Saclay colleagues Yves Gasser and Fabien Eozénou for chemical treatments.

[1] B. Visentin, J. P. Charrier, and B. Coadou, in Proceedings of the 6th European Particle Accelerator Conference, Stockholm, Sweden, 1998, edited by S. Myers, R. Pascual, A. Pacheco, Ch. Petit-Jean-Genaz, and J. Poole (IOP, London, 1998), paper TUP07B, p. 1885, available from http://accelconf.web.cern.ch/AccelConf/e98/papers/ tup07b.pdf.

[2] B. Visentin, Y. Gasser, and J.P. Charrier, Physica C (Amsterdam) 441, 66 (2006).

[3] B. Visentin, J. P. Charrier, Y. Gasser, and S. Regnaud, in Proceedings of the 10th European Particle Accelerator
Conference, Edinburgh, Scotland, 2006, edited by C. Biscari, H. Owen, Ch. Petit-Jean-Genaz, J. Poole, and J. Thomason (EPS-AG, Edinburgh, Scotland, 2006), paper MOPCH141, p. 381, available from http://accelconf.web. cern.ch/AccelConf/e06/papers/mopch141.pdf.

[4] B. Visentin et al., in Proceedings of the 13th International Workshop on RF Superconductivity, Beijing, China, 2007, edited by J. Hao, S. Huang, and K. Zhao (PKU, Beijing, China, 2008), paper TuP69, p. 304, available from http:// accelconf.web.cern.ch/AccelConf/srf2007/papers/tup69. pdf.

[5] M. Delheusy, Ph.D. thesis, Paris-Sud XI and Stuttgart Universities, 2008, p. 130.

[6] G. Ciovati and A. Gurevich, Phys. Rev. ST Accel. Beams 11, 122001 (2008).

[7] A. Romanenko, in Proceedings of the 14th International Conference on RF Superconductivity, Berlin, Germany, 2009 (Ref. [14]), paper TUOAAU02, p. 95, available from http://accelconf.web.cern.ch/AccelConf/srf2009/papers/ tuoaau02.pdf.

[8] J. Halbritter, in Proceedings of the 14th International Conference on RF Superconductivity, Berlin, Germany, 2009 (Ref. [14]), paper TUPPO089, p. 450, available from http://accelconf.web.cern.ch/AccelConf/srf2009/ papers/tuppo089.pdf.

[9] T. Proslier et al., Appl. Phys. Lett. 92, 212505 (2008).

[10] H. Kugler, I. A. Schwirtlich, S. Takaki, K. Yamakawa, U. Ziebart, J. Petzold, and H. Schultz, in Proceedings of the 5th Yamada Conference on Point Defects and Defect Interactions in Metals, Kyoto, Japan, 1981, edited by J. I. Takamura, M. Doyama, and M. Kiritani (University of Tokyo Press, Tokyo, 1982), p. 520.

[11] H. Schultz, in Proceedings of the 5th Yamada Conference on Point Defects and Defect Interactions in Metals, Kyoto, Japan, 1981 (Ref. [10]), p. 183.

[12] M. Haaf, H. E. Schaefer, and W. Frank, in Proceedings of the 6th International Conference on Positron Annihilation, Arlington, Texas, 1982, edited by P.G. Coleman, S.C. Sharma, and L.M. Diana (North-Holland Publishing Company, Amsterdam, 1982), p. 446.

[13] P. Hautojarvi, H. Huomo, M. Puska, and A. Vehanen, Phys. Rev. B 32, 4326 (1985).

[14] B. Visentin, M. F. Barthe, P. Desgardin, and V. Moineau, in Proceedings of the 14th International Conference on RF Superconductivity, Berlin, Germany, 2009, edited by M. Abo-Bakr, B. Kuske, A. Liebezeit, S. Voronenko, and V. Schaa (SRF, Berlin, 2009), paper TUPPO047, p. 326, available from http://accelconf.web.cern.ch/AccelConf/ srf2009/papers/tuppo047.pdf.

[15] P. Hautojarvi and A. Vehanen, in Positron in Solids, edited by P. Hautojarvi (Springer-Verlag, Berlin, 1979), Chap. 1, p. 1.

[16] P. Desgardin et al., Mater. Sci. Forum 363, 523 (2001).

[17] H. Padamsee, in RF Superconductivity: Science, Technology and Applications (Wiley-VCH, Weinheim, 2009), Pt. 1, Chap. 3, p. 66.

[18] B. Bonin and R.W. Roth, in Proceedings of the 5th International Workshop on RF Superconductivity, Hamburg, Germany, 1991, edited by D. Proch (DESY, Hamburg, 1992), p. 210.

[19] G. Ciovati, J. Appl. Phys. 96, 1591 (2004). 
[20] J. Cizek et al., Phys. Rev. B 79, 054108 (2009).

[21] J. Volkl and G. Alefeld, in Hydrogen in Metals I Basic Properties, edited by G. Alefeld and J. Volkl (SpringerVerlag, Berlin, 1978), Chap. 12, p. 321.

[22] B. Visentin, in ICFA Beam Dynamics Newsletter, edited by K. J. Kim (2006), Vol. 39, Chap. 3, p. 94, available from http://icfa-usa.jlab.org/archive/newsletter.shtml.

[23] R. Krause-Rehberg and H.S. Leipner, Positron Annihilation in Semi-conductors, Springer Series in Solid State Sciences 127 (Springer, New York, 1999). 